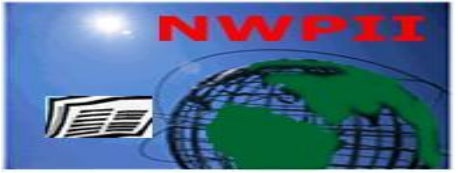

\title{
Haptoglobin Phenotypes and Association with Vascular Complications in Nigerian Type 2 Diabetes Patients
}

\section{${ }^{1}$ Olayinka Olaolu OLANIYAN, ${ }^{2}$ Humphrey B OSADOLOR}

\author{
${ }^{1}$ Department of Chemical Pathology, Osun State University, Osogbo, Osun State, Nigeria \\ ${ }^{2}$ Department of Medical Laboratory Science,University of Benin, Benin, Edo State, Nigeria \\ *Corresponding Author \\ O.O. Olaniyan \\ Department of Chemical pathology \\ Osun State University \\ Osogbo \\ Nigeria \\ Cell Phone: +2348034766014 \\ Email:olacube2001@gmail.com
}

Received: 01 July 2018; | Revised:23 July 2018; | Accepted: 10 September 2018

\begin{abstract}
Haptoglobin phenotypes were determined in 120 type 2 diabetes mellitus (including 60 diabetics with vascular complications and 60 diabetics without any vascular complications) and were compared to 50 apparently healthy individuals. A higher frequency of Hp 2 allele gene and Hp 2-2 phenotype was observed in diabetics and diabetics with vascular complications respectively. We found an association between Hp 2 allele in type 2 diabetes mellitus and Hp 2-2 phenotypes in diabetics with vascular complications. Hence, we conclude that screening diabetics for Hp 2-2 phenotypes would be an added advantage in patient focus management.
\end{abstract}

Keywords: Haptoglobin phenotypes, Type 2 Diabetes, Vascular complications, Nigerian

\section{Introduction}

Haptoglobin (Hp) an a 2-sialoglycoprotein ${ }^{[1]}$ that is synthesized majorly by the hepatic and also by kidney, skin and lung tissues ${ }^{[2]}$, is a positive acute phase reactant haemoglobin binding protein that binds free oxygenated haemoglobin produced in response to infection or inflammation through induction by interleukins (IL-6, IL-1) and tumour necrosis factor- $\alpha$ (TNF- $\alpha)^{[3]}$. In man $\mathrm{Hp}$ is expressed by a genetic polymorphism of the $\alpha$-chain to form three major phenotypes commonly referred to as $\mathrm{Hp} 1-1$, Hp2-1, and $\mathrm{Hp} 2-2^{[4]}$. Hp 2-1M phenotype is more frequent in African population ${ }^{[5]}$ and has been shown to have greater number of $\mathrm{Hp} 1$ bands ${ }^{[6]}$ generated by the polymorphism of a single nucleotide in the promoter region of the $\mathrm{Hp} 2$ gene [4].

The occurrence of these polymorphism at the haptoglobin locus has make it a potential genetic 
marker and motivated many investigations directed at the determination of possible associations between haptoglobin $(\mathrm{Hp})$ and different disorders [6]. The significance of this polymorphism in diabetes mellitus has also been investigated. Several prospective and cross-sectional population studies have demonstrated an association of the Hp 2 gene and Hp 2-2 phenotype as an independent risk factor for diabetes and development of vascular disease in diabetes mellitus ${ }^{[7-10]}$. Therefore, the aim of this present study was to investigate the association between Hp gene phenotype and incidence of type 2 diabetes mellitus in a Nigerian population.

\section{Materials and Methods}

Blood samples (plasma) were obtained from 120 adult patients with type 2 diabetes mellitus at a tertiary health facility in Osogbo, Osun State, and Southwest Nigeria. Diabetes patients were diagnosed according to WHO criteria ${ }^{[1]}$ and classified into two main groups of those without vascular complications (DM-VC, $\mathrm{n}=60$ ), and those with vascular complications $(\mathrm{DM}+\mathrm{VC}, \mathrm{n}=60)$ based on the presence or absence of any complications due to diabetes mellitus. The control group (CG) comprises 50 apparently healthy non-diabetes individuals with no personal or family history of either diabetes or dyslipidemia selected from among the Osun State University staff. Neither DM patients nor healthy controls were smokers and were not receiving vitamin or mineral supplements for the past 1 month. Control groups were not taking any drugs known to affect carbohydrate or lipid metabolism. All of the subjects enrolled in the present study were of Yoruba ethnicity in southwest Nigeria (to avoid mixed population and ancestral differences). Written informed consent was taken from all the participants and all the experiments strictly adhered to the tenets of the Helsinki declaration. The study protocol was approved by the Ethical Committee of the Osun State University.
Hp phenotypes were determined by acidic urea polyacrylamide gel electrophoresis (PAGE) as previously described ${ }^{[12-13]}$, in brief, $6 \mu 1$ of plasma samples were incubated with $1 \mu 1$ of erythrocyte haemolysate of washed human red blood cells. $6 \mu \mathrm{l}$ of loading buffer was then added to the mixture and $8 \mu \mathrm{l}$ from the resultant mixture were loaded onto the gel for electrophoresis, after migration, proteins were fixed using $10 \%$ trichloroacetic acid solution and stained with benzidine solution. The bands were then observed for Hp phenotype fractions.

Hardy-Weinberg equilibrium (HWE) was used to calculate $\mathrm{Hp}$ phenotypic distribution and allelic frequencies. Groups were compared with each other using chi square and odd ratio of Vassar Stats (http://vassarstats.net/index.html) online software (assessed on 2nd of June, 2018).

\section{Results}

Table 1 demonstrates that the frequency of the haptoglobin phenotype and allele distribution while table 2 shows the odd ratio existing in the study population respectively. Hp 1-1 in type 2 diabetics which was $9.17 \%$ was significantly lower ( $\mathrm{p}<0.0001)$ than the control subjects $46.00 \%$, while, the frequency of Hp 2-2 in type 2 diabetics $(42.33 \%)$ was significantly higher $(\mathrm{p}<0.0001)$ than in control subjects $(12.00 \%)$. Likewise, Hp 2-2 frequency of $55 \%$ in diabetics with vascular complications was significantly greater $(p<0.001)$ than in diabetics without vascular complications $(31.67 \%)$. On the other hand, there was no significant difference $(p>0.05)$ between in the frequency of Hp 2-1 in diabetics (42.333\%) and control subjects (42.00), and also between diabetics with vascular complications $(55.00 \%)$ and diabetics without vascular complications (31.67\%). respectively. 
Table 1:Haptoglobin phenotype distribution and allele frequency among the study Population

\begin{tabular}{|c|c|c|c|c|c|c|}
\hline \multirow[b]{2}{*}{ Groups } & \multicolumn{4}{|c|}{ Haptoglobin phenotypes distribution } & \multicolumn{2}{|c|}{ Hp Allele frequency } \\
\hline & $\overline{\mathrm{Hp}}$ & $\overline{1-1}$ & $2-1$ & $2-2$ & Hp1 & Hp 2 \\
\hline \multicolumn{2}{|c|}{ Control group } & $23(46.00 \%)$ & $21(42.00 \%)$ & $6(12.00 \%)$ & 0.654 & 0.346 \\
\hline \multicolumn{2}{|c|}{ Type 2 Diabetes } & $11(9.17 \%)$ & $57(47.50 \%)$ & $52(42.33 \%)$ & 0.349 & 0.651 \\
\hline \multicolumn{2}{|c|}{ DM - VC } & $8(13.33 \%)$ & $33(55.00 \%)$ & $19(31.67 \%)$ & 0.437 & 0.563 \\
\hline \multicolumn{2}{|c|}{$\mathrm{DM}+\mathrm{VC}$} & $3(5.00 \%)$ & $24(40.00 \%)$ & $33(55.00 \%)$ & 0.258 & 0.742 \\
\hline
\end{tabular}

Result presented as no (\%)

no $=$ number of subjects

$\%=$ percentage of subjects

$\mathrm{DM}-\mathrm{VC}=$ diabetics without vascular complications

$\mathrm{DM}+\mathrm{VC}=$ diabetics with vascular complications

Hp = Haptoglobin

Table 2:Odd ratio table for developing type 2 diabetes and vascular complications in type 2 diabetes

\section{Haptoglobin phenotypes}

\begin{tabular}{llll}
\cline { 2 - 3 } Groups & Hp 1-1 & Hp 2-1 & Hp 2-2 \\
\hline
\end{tabular}

Type 2 diabetics/non diabetes

$\begin{array}{lccc}\text { ODD Ratio }(95 \% \mathrm{CI}) & 0.12(0.52-.27) & 1.25(0.64-1.48) & 5.61(2.22-14.16) \\ \text { p-value } & <0.00 & 0.51 & <0.00\end{array}$

\section{DM-VC/non diabetes}

ODD Ratio $(95 \% \mathrm{CI})$

p-value

$$
\begin{array}{ccc}
0.18(0.07-0.46) & 1.69(0.79-3.60) & 3.40(1.24-9.35) \\
0.00 & 0.17 & 0.01
\end{array}
$$

\section{$\mathrm{DM}+\mathrm{VC} /$ non diabetes}

ODD Ratio (95\% CI)

$$
\begin{array}{ccc}
0.06(0.02-0.22) & 0.92(0.43-1.97) & 8.96(3.32-24.20) \\
<0.00 & 0.82 & <0.00
\end{array}
$$

$\mathrm{P}$-value

\section{DM-VC/DM+VC}

ODD Ratio $(95 \% \mathrm{CI})$

$$
0.34(0.09-1.36) \quad 0.55(0.26-1.13) \quad 2.66(1.25-5.55)
$$

p-value

0.11

0.10 0.01

Values presented in 2 decimal places

$\mathrm{Hp}=$ Haptoglobin

$\mathrm{DM}+\mathrm{VC}=$ diabetics with vascular complications

$\mathrm{DM}-\mathrm{VC}=$ diabetics without vascular complications 


\section{Discussion and Conclusion}

The key to reducing the burden (morbidity and mortality) of diabetes mellitus disease is early detection and timely therapeutic interventions. Nigeria is known to have the highest number of individuals living with diabetes mellitus in subSaharan Africa ${ }^{[14]}$, and despite, reporting contrast opinions linking haptoglobin polymorphism with DM by various studies worldwide, Nigeria data on haptoglobin and diabetes mellitus still remain scanty.

Haptoglobin, an acute phase protein acting as an antioxidant by virtue of its ability to bind free haemoglobin and prevent hae.me-iron mediated oxidation ${ }^{[15]}$ is found to be phenotypically associated with type 2 diabetes from our study. The result of this study showed that $\mathrm{Hp} 2$ allele is a dependent factor in type $2 \mathrm{DM}$ in Nigerians therefore, suggesting a strong association between the haptoglobin allele and particularly Hp 2-2 phenotypes in diabetics with vascular complications. This study therefore agrees with Quaye et al ${ }^{[16]}$, Adinortey, et al.., ${ }^{[17]}$ and Amiri et al., [18] who demonstrated association between diabetes mellitus and Hp 2-2 phenotype in their study populations where as, the result is in contrast to the report of Awadallah and Hamad ${ }^{[19]}$ who reported no association between haptoglobin and diabetes in the Jordanian population.

Free haemoglobin (produced during Fenton reaction) increases the rate of oxidized LDL which can cause endothelia dysfunction and consequently vascular complications in diabetes ${ }^{[20]}$. It has also been proven that CD163/Hp1-1-Hb complex scavenge free haemoglobin efficiently and effectively than $\mathrm{CD} 163 / \mathrm{Hp} 2-2 \mathrm{Hb}$, with the haemoglobin binding capacity and antioxidant function of $\mathrm{Hp} 1$ more than that of $\mathrm{Hp} 2^{[16]}$. Thus, linking the role of haptoglobin phenotypes in diabetes risk directly to its function as an antioxidant would not be out of place.

None of the subjects from our study population was of Hp 2-1M phenotypes which was claimed to be common haptoglobin polymorphism in Africa ${ }^{[5,12]}$ though, the reason for non-occurrence of this phenotype is unknown, but might not be unconnected to our study population which are homogenous in nature (only one ethnic group), and the potential limitation posed by the small sample size which may confer bias on the phenotype distribution and allele frequency of haptoglobin. Thus, we advocate further study with large sample size among different Nigerian ethnic groups.

Summarily from our study, we conclude that Hp 2 allele is a risk factor for type 2 diabetes and that $\mathrm{Hp}$ 2-2 phenotype predisposes to vascular compilations in Nigeria type 2 diabetics. Thus, screening of type 2 diabetics for Hp phenotypes could be an essential therapeutic assessment tool in patient focus treatment.

\section{References}

1 Bessa SS, Hamdy SM, Ali EM. Haptoglobin gene polymorphism in type 2 diabetic patients with and without nephropathy: An Egyptian study. Eur J Intern Med 2007; 18(6): 489-495 DOI: $10.1016 /$ j.ejim.2007.02.033

2 Trayhurn P, Wood IS. Adipokines: inflammation and the pleiotropic role of white adipose tissue. Br J Nutr 2004; 92(3): 347-355 [PMID: 15469638]

3 Wang Y, Kinzie E, Berger FG, Lim SK, Baumann H. Haptoglobin, an inflammationinducible plasma protein. Redox Rep 2001; 6(6): 379-385

DOI: $10.1179 / 135100001101536580$

4 Amiri AA, Hashemi-Soteh MB, Haghshenas MR, Daneshvar F, Rastegar A, Farazmand T. Haptoglobin polymorphism in individuals with type 2 diabetic microangiopathy. $\mathbf{N} \mathbf{A m} \mathbf{J}$ Med Sci 2013; 5(9): 529-535

DOI: $10.4103 / 1947-2714.118929$

5 Maeda N. DNA polymorphisms in the controlling region of the human haptoglobin genes: a molecular explanation for the haptoglobin 2-1 modified phenotype. Am $\boldsymbol{J}$ Hum Genet 1991; 49(1): 158-166 [PMID: 2063867 PMCID: PMC1683214] 
6 Carter K, Worwood M. Haptoglobin: a review of the major allele frequencies worldwide and their association with diseases. Int $\boldsymbol{J} \mathbf{L a b}$ Hematol 2007; 29(2): 92-110 DOI: 10.1111/j.1751-553X.2007.00898.x

7 Levy AP, Hochberg I, Jablonski K, Resnick HE, Lee ET, Best L, Howard BV, Strong Heart $\mathrm{S}$. Haptoglobin phenotype is an independent risk factor for cardiovascular disease in individuals with diabetes: The Strong Heart Study. J Am Coll Cardiol 2002; 40(11): 19841990 [PMID: 12475459]

8 Suleiman M, Aronson D, Asleh R, Kapeliovich MR, Roguin A, Meisel SR, Shochat M, Sulieman A, Reisner SA, Markiewicz W, Hammerman H, Lotan R, Levy NS, Levy AP. Haptoglobin polymorphism predicts 30-day mortality and heart failure in patients with diabetes and acute myocardial infarction. Diabetes 2005; 54(9): 2802-2806 [PMID: 16123372]

9 Nakhoul FM, Marsh S, Hochberg I, Leibu R, Miller BP, Levy AP. Haptoglobin genotype as a risk factor for diabetic retinopathy. JAMA 2000; 284(10): 1244-1245 [PMID: 10979109]

10 Nakhoul FM, Miller-Lotan R, Awaad H, Asleh R, Levy AP. Hypothesis--haptoglobin genotype and diabetic nephropathy. Nat Clin Pract Nephrol 2007; 3(6): 339-344 [PMID: 17525716 DOI: $10.1038 /$ ncpneph0467]

11 World Health Organisation. Definition and diagnosis of diabetes mellitus and intermediate hyperglycemia: report of a WHO/IDF consultation. WHO Library Cataloguing-inPublication Data. 2006; ISBN 978924 1594936

12 Adinortey MB, Gyan BA, Adjimani JP, Nyarko PE, Sarpong C, Tsikata FY, Nyarko AK. Haptoglobin polymorphism and association with complications in ghanaian type 2 diabetic patients. Indian $J$ Clin Biochem 2011; 26(4): 366-372 DOI: 10.1007/s12291-011-0141-3

13 Davis BJ. Disc Electrophoresis. Ii. Method and Application to Human Serum Proteins. Ann N Y Acad Sci 1964; 121: 404-427 [PMID: 14240539]

14 Dahiru T, Aliyu AA, Shehu AU. A review of population-based studies on diabetes mellitus in Nigeria. Sub-Saharan Afr J Med 2016; 3:59-64.

15 Dahan I, Farber E, Thauho N, Nakhoul N, Francis A, Awawde M, Levy AP, Kim-Shapiro DB, Basu S, Nakhoul F. Interaction between the Haptoglobin 2 Phenotype and Diabetes Mellitus on Systolic Pulmonary Arterial Pressure and Nitric Oxide Bioavailability in Hemodialysis Patients. J Diabetes Res 2015; 2015: 613860 DOI: $10.1155 / 2015 / 613860$

16 Quaye IK, Ababio G, Amoah AG. Haptoglobin 2-2 phenotype is a risk factor for type 2 diabetes in Ghana. J Atheroscler Thromb 2006; 13(2): 90-94 [PMID: 16733296]

18 Amiri AA, Hashemi-Soteh MB, Haghshenas MR, Daneshvar F, Rastegar A, Farazmand T. Haptoglobin polymorphism in individuals with type 2 diabetic microangiopathy. N Am J Med Sci 2013; 5(9): 529-535 DOI: 10.4103/19472714.118929

19 Awadallah S, Hamad M. The prevalence of type II diabetes mellitus is haptoglobin phenotype-independent. Cytobios 2000; 101(398): 145-150 [PMID: 10755213]

20 Lim SK, Ferraro B., Moore, Halliwell, B. Role of haptoglobin in fre haemoglobin metabolism. Redox Rep.2001; 6:219. 